\title{
Strategies for Enhancing Effective Teacher Performance
}

\author{
Tsitsi Dhliwayo*, Thembinkosi Tshabalala
}

National Teaching Practice Coordinator: Faculty of Education: Zimbabwe Open University Zimbabwe

DOI: $10.36347 /$ sjahss.2020.v08i02.005

| Received: 10.02.2020 | Accepted: 17.02.2020 | Published: 27.02.020

*Corresponding author: Tsitsi Dhliwayo

Abstract

Quality teaching and student learning are tightly interconnected. Together they form two sides of a triangle. The third side of this triangle is often overlooked, but is also integral to teaching quality and student learning-quality instruction and preparation for teachers. Unfortunately, all too often, the children who could benefit most from quality teaching children in low-income contexts, in crisis or conflict settings, in remote or remote geographical environments - have little exposure to quality teaching. And unfortunately, all too often, in these same settings, the teachers who could benefit most from quality professional development (PD) that would equip them with the skills to help more children learn either receive no PD or take part in ineffective professional development.

Keywords: Professional development, quality teaching, students learning, enhancing, teacher children.

Copyright @ 2020: This is an open-access article distributed under the terms of the Creative Commons Attribution license which permits unrestricted use, distribution, and reproduction in any medium for non-commercial use (NonCommercial, or CC-BY-NC) provided the original author and source are credited.

\section{INTRODUCTION}

Effectiveness can be documented by evaluating teaching practices that are associated with desired student outcomes and the achievement of school goals through systematic collection of evidence about teacher planning and instruction. Dilworth and David [1] argue that effective teacher teaching is reflected by the student achievements in school work. Admittedly, non-school factors do influence the achievement of students as well but effective teaching has the potential to help level the playing field [2]. Medley [3] states that effective teachers are those who achieve the goals which they set for themselves or which have been set for them by others (for example, ministries of education, legislators and other government officials as well as school administrators). As a consequence, those who study and attempt to improve teacher effectiveness must be cognisant of the goals imposed on teachers or the goals that teachers establish for themselves or both. A corollary of this definition is that effective teachers must possess the knowledge and skills needed to attain the goals, and must be able to use that knowledge and those skills appropriately if these goals are to be achieved [4].

\section{Effective professional development}

Effective professional development has been described as professional growth opportunities that truly have an impact on teacher learning and ultimately enhance student achievement [5-7]. Since the early 1990's, there have been multiple studies to determine what effective professional development looks like [8, $6,9]$. The purpose of the National Staff Development Council (NSDC) is to provide continuous research on best practices for professional development. Rasmussen et al. [10] suggest that effective professional development is coherent, research based, and capacity building (p. 19). A professional consensus of the overall characteristics of effective professional development is described by Desimone et al. [5] as being focused on:

How students learn content; in-depth, active learning opportunities; links to high standards, opportunities for teachers to engage in leadership roles; extended duration; and the collective participation of groups of teachers from the same school, grade, or departments (p. 82). This consensus was formed based on the results of a three-year longitudinal study with 30 schools and 207 teachers.

According to Guskey [6], for professional development to be deemed as effective, it must first have a significant impact on student learning. Teachers must be at the forefront to receive and implement the strategies that are introduced through effective staff development. McLaughlin and Talbert [11] suggest that researchers agree that teachers learn best when they are involved in activities that specifically focus on instruction and student learning within identified school settings. According to Hord [12], when professional 
development addresses the needs of the school that are identified through data, the learning has a greater impact. McLaughlin and Talbert [13] also stress that effective staff development should be a continuous process that constantly involves an element of reflection and evaluation. Through collaboration with colleagues, teachers should be provided with the opportunities to process and construct a theoretical understanding of their skills and knowledge through a continuous cycle of inquiry and improvement. Teachers are then empowered to share and act on their learning.

Effective professional development is diversified and revolves around the issues that are relevant to a school's population [7]. The framework for effective professional development must be based on the identified needs of the students, staff, and the culture of a particular school. Therefore, appropriate professional development needs will result from analysis and synthesis of all available data [6]. According to Sargent [14], there are four categories of data that will assist in determining the overall needs of the representative student population, including student achievement, demographics, programme, and perception data. Teachers and administrators must take an active role in the process of analysis and in determining the needs of the school. The identified needs should be the driving force for the types of professional development opportunities that teachers and Administrators seek [10].

The implementation and sustainability of strategies learned through effective staff development are based on a continuous and ongoing process of reflective learning. From a large-scale empirical comparison study conducted by Garet et al. [8] using a national probability sample, three characteristics of effective professional development surfaced. According to the study, effective professional development must focus on content knowledge, engage teachers in the learning process, and be coherent with other learning opportunities. The study revealed that teachers and administrators must be involved in a process of learning and change to effectively implement innovative instructional strategies that will enhance the students' opportunities for learning. An essential element of this process is the opportunity for teachers to reflect and participate in professional dialogue with their colleagues [11]. Professional dialogue provides opportunity for feedback and assistance in the implementation of new ideas. Guskey [6] incorporates the idea that effective professional development requires that teachers work together, reflect on their practice, exchange ideas, and share strategies (p. 749).

Along with the opportunity for professional, collaborative dialogue and reflective evaluation, effective professional development must also be coupled with facilitative coaching and peer observation [15]. Coaching and peer observations afford teachers the opportunities to gain constructive insight from their colleagues about specific instructional practices. Teachers involved in this practice of professional development are engaged in focused recurring cycles of instruction, assessment, and adjustment of instruction [16]. Hirsh [17] asserts that professional development must be results-driven, standards-based, and jobembedded (p. 4). The term "job embedded is characterised by the National Staff Development Council (NSDC) as schools where goals are continuously aligned and monitored to support the needs that have been identified through the disaggregation of data. Ongoing reviews of the data enable teachers to evaluate progress and design appropriate professional development opportunities to meet the desired goals. Hirsh [17] avows that effective professional development focuses on deepening educator's content knowledge, by applying researchbased strategies to help students meet rigorous standards, and using a variety of classroom assessments (p. 22). Darling-Hammond [18] asserts, the most effective staff development is curriculum based, sustained over time, linked to concrete problems of practice and built into teachers' ongoing work with their colleagues (p. 8).

\section{Professional learning communities}

In response to the cry for more effective professional development, schools have begun investigating various strategies for implementing professional growth opportunities. One concept that has provided school with a road map for creating opportunities for effective professional development has been the implementation of professional learning communities. During the early 1990's, many schools began the process of reform by developing professional learning communities within the school environment [12]. Burnette [3] defines a professional learning community as:

A school where people are united by a common purpose, shared vision, collective commitments, and specific, measurable goals; where collaborative teams engage in action research and collective inquiry into the big questions of teaching and learning; where continuous improvement cycles are built into the routine practices of the school and where gathering evidence of student learning is a constant focus (p. 52).

This systemic structure for professional development creates a continuous learning environment for teachers and administrators with the primary objective aimed towards student achievement. In a case study of Cottonwood Creek School, conducted by a research team from Southwest Educational Development Lab (SEDL) [15], it was found that, the factors that make it possible for students to grow and develop (provision of stimulating and relevant material, 
processing the material in a social context, feedback on performance, support and encouragement, etc.) are the same that enable professional staff to grow and develop (p. 7). These characteristics found at Cottonwood Creek School have enhanced the professional growth of teachers. During this study, the team conducted more than 30 interviews of various stakeholders within the school environment.

The interviews also revealed that the staff was continuously engaged in reflection, assessment, evaluation, study and learning. Professional learning communities focus on the specific issues and needs that are relevant to the school. These issues are discovered through a methodical analysis of all available sources of data. Learning communities allow teachers and administrators to make collaborative data driven decisions that will promote positive and lasting change in regards to their school's identified areas of concern. Dufour, Eaker and Dufour [19] argue the powerful collaboration that characterises professional learning communities is a systematic process in which teachers work together to analyse and improve their classroom practice" (p.36). Professional learning communities break down the walls that create the isolation and provide teachers with the opportunities to reflect, evaluate, and improve their teaching practices through professional collaboration [12]. Dufour [19] emphasises that in professional learning communities, teachers work in teams, "engaging in an ongoing cycle of questions and promote deep team learning (p. 9). Collaboration assists in the cultivation of professional confidence and nurtures the translation of new ideas to practice [20]. The confidence that emerges encourages teachers to interact with the educational environment more assertively and allows a safety net that upholds a high level of risk taking [21]. These safety nets support the use of innovative research based practices that promotes appropriate learning environments for all children [3].

A collaborative community of professional learners promotes a significant change in the mindset of teachers. The priorities of their mission as teachers, changes from the concept of teaching to the concept of learning. Teaching is no longer the primary focus, it is learning. Dufour [19] notes that teachers of a professional learning communities focus on the question, how will we know when each student has learned? (p. 9). The objectives of the professional learning community center around researching strategies that will meet the needs of the individual child. This community of learners also discusses opportunities for assessment and evaluation as an avenue for determining individual student success. When instructional strategies are not successful, the team, not the individual teacher, works together to research ideas that could bring about success for the students served [13].
The systematic process that evolves from the creation of professional learning communities affords teachers and administrators the time to understand problems and investigate potential solutions. Schools organised in this way see problems as opportunities to learn and not as barriers that are difficult to overcome $[12,20]$. Teachers who are committed to working together find solutions that ensure that all children learn [19]. Collaborative environments focus on the relationships and connections among individuals [21]. The connections that are revealed promote a more nurturing and compassionate environment. Harris [21] goes on to explicate that collaborative environments are separated from person, role, and status reflecting instead the dynamic created out of shared purpose and being part of a school community (p. 22). This ownership sparks a desire and commitment for implementing change that potentially contributes to success. Louis and Kruse [15] argue that change and improvement occurs because the individuals and the groups inside the school are able to acquire, analyse, understand and plan around information that arises from the environment and from internal monitoring (p. 18).

To create professional learning community, teams must be afforded the opportunities to meet on a regular basis. The NSDC recommends that teams meet at least once, but preferably several times a week [17]. Meeting on a regular basis develops a sense of ownership of the problems that are discussed and ultimately creates opportunities for collegiality and collaboration. Because the meetings focus on the purpose of learning with joint lesson planning and problem solving, an atmosphere of professional learning begins to form. According to Roy and Hord [12], professional learning communities also operate with a commitment to the norms of continuous improvement and experimentation that engage their members in improving daily work to advance the achievement of school goals for student learning ( $\mathrm{p}$. 13).

\section{Products of professional learning communities}

The overall positive results of the creation of professional learning communities are numerous. Teachers no longer experience the frustration of isolation. The walls of their classrooms are extended beyond the walls of the school and unlimited doors of learning are unlocked. According to a report from SEDL [12], teachers also experience a heightened commitment to the goals for the school and develop collective responsibility for students' success. Teachers develop a more informed understanding of the powerful learning that defines good teaching (p. 6). The NSDC [19] conducted research in five states that focused on the professional development practices. Researchers found that teachers involved in professional learning communities experienced powerful opportunities for shared leadership and learning such as working together on developing the state learning standards, the state 
strategic planning initiative, the state math initiatives, and professional development projects (p. 32). Researchers at SEDL [12] also found that teachers involved in professional learning communities are professionally renewed and inspired to inspire students (p. 6). Because of the renewed spirit, morale in professional learning community schools is significantly higher. Teachers develop a strong sense of ownership and become committed to providing the best educational experiences for all children.

\section{School Improvement through professional learning communities}

School improvement is marked by the opportunities for constant interchange of professional information within the school environment [21]. During a three-year case study conducted by Strahan [20], a team of researchers compared previous data collected from a case study analysis with data collected from new interviews and meeting and classroom observations. The schools involved in the study had improved their achievement on state achievement test from less than $50 \%$ to more than $75 \%$. The data gathered from the case study revealed that the success of three schools was attributed to the development of professional learning communities. The professional learning communities created at the identified schools were enhanced by a supportive, nurturing culture that encouraged participants to coordinate efforts to improve instruction (p. 127). Based on the findings of Strahan's research, this type of educational culture is embedded with data driven dialogue, purposeful conversations, guided by formal assessment and informal observations that connected the ways adults and students cared for each other and that provided energy to sustain their efforts (p. 127).

\section{CONCLUSION}

As with any vocation, teachers need to develop strong identities as professionals. In addition to obvious factors such as recruitment, remuneration, and opportunities for advancement, teacher professionalism is also impacted by access to quality professional development. It's hard to feel like a professional when you don't feel competent, when you get no training or support, when you teach children with severe academic and emotional needs and when you have no idea how to address these needs. But not simply any PD will do. As the guide notes, teacher professional development must focus on helping teachers employ "high-yield" instructional practices-formative assessment, feedback, clarity in explanation that have shown direct measurable impacts on student learning.

\section{REFERENCES}

1. Dilworth $\mathrm{C}$ and David M. Evidence based continuing education. Economic and Workshop Division. 1995; 337(10): 521-538.
2. Corcoran PS. Recruiting and retaining adult students. New Directions for Adult and Continuing Education.1995; (10); 4: 14-34.

3. Andrews D and Lewis M. Building capacity: Teachers thinking and working together to create new futures. Journal of School Leadership. 2002; 16(5): 534-549.

4. Daniel D and Lindsay D. Leadership in education. Auckland: Auckland University; 2008.

5. Desimone LM, Porter AC, Garet MS, Yoon KS, Birman BF. Effects of professional development on teachers' instruction: Results from a three-year longitudinal study. Educational evaluation and policy analysis. 2002 Jun;24(2):81-112.

6. Guskey TR. What makes professional development effective?. Phi delta kappan. 2003 Jun;84(10):74850.

7. Sparks SD. Teachers shape students' motivation. Where do they learn how to do it? Education week.2004; 3(6): 15-26.

8. Garet MS, Porter AC, Desimone L, Birman BF, Yoon KS. What makes professional development effective? Results from a national sample of teachers. American educational research journal. 2001;38(4):915-45.

9. Wilson SM, Berne J. Chapter 6: Teacher Learning and the Acquisition of Professional Knowledge: An Examination of Research on Contemporary Professlonal Development. Review of research in education. 1999 Jan;24(1):173-209.

10. British Educational Research Association. Revised ethical guidelines for educational research. Bera; 2004.

11. McLaughlin MW, Talbert JE. Building schoolbased teacher learning communities: Professional strategies to improve student achievement. Teachers College Press; 2006.

12. Hord SM. Professional learning communities of continuous inquiry. Educational Development Library.1997; 13(4): 115-126.

13. McLaughlin MW, Talbert JE. Building schoolbased teacher learning communities: Professional strategies to improve student achievement. Teachers College Press; 2006.

14. Hansen L, Sargent TJ. Robust control and model uncertainty. American Economic Review. 2001 May;91(2):60-6.

15. Louis KS, Marks HM. Does professional community affect the classroom? Teachers' work and student experiences in restructuring schools. American journal of education. 1998 Aug 1;106(4):532-75.

16. Schmoker M. Evaluating the essentials to radically improve student learning. Association of Education Publishers.2004; 6(4): 19-36.

17. Hirsh W. The development of management and leadership capability and its contribution to performance. The evidence, the prospects and the research need. Lancaster: Lancaster University; 2004. 
18. Darling-Hammond L. Teacher learning that supports student learning. Review of Research in Education.1996; 19(6) 59-72.

19. Dufor R, Eaker R and Dufour R. On common ground: The power of professional learning communities. Paris: Solution Tree; 2005.

20. Straham D. Promoting a collaborative culture in three elementary schools that have beaten the odds.
The Elementary School Journal. 2003; 104(2) 7993.

21. Harris CM, Piersol AG. Harris' shock and vibration handbook. New York: McGraw-Hill; 2002.

22. Birman $\mathrm{N}$ and Yoon T. Collective professional knowledge. Medical Education. 2001; 34(6): 505506. 